\title{
The influence of tool micro-geometry on stress distribution in turning operations of AISI 4140 by FE analysis
}

\author{
Mathias Agmell $^{1} \cdot$ Aylin Ahadi $^{1}$ - Oleksandr Gutnichenko ${ }^{1} \cdot$ Jan-Eric Ståhl $^{1}$
}

Received: 13 April 2016 / Accepted: 1 August 2016 / Published online: 15 August 2016

(C) The Author(s) 2016. This article is published with open access at Springerlink.com

\begin{abstract}
The aim of this paper is to gain a better understanding of the impact different micro-geometries has on stress distribution in cutting tools. Both principal and effective stress distribution are studied. These quantities have a major impact on the occurrence of damages in the cutting tool such as crack formation, flaking, chipping, breakage and plastic deformation. The development of a stagnation zone is also investigated as well as the effect tool microgeometries have on this zone. A finite element model is developed which enables the examination of these aspects, in detail. It was found that the model predicted these metal cutting phenomena with high accuracy. Cutting forces is within the standard deviation of experimental results. The experimental results also indicate that the stress distributions and the stagnation zone have been simulated correctly. This study has shown that the micro-geometries of the cutting tool have a great potential in reducing the maximal tensile/principal stress. This research work has also shown that the size of the stagnation zone can be controlled by micro-geometries on the cutting tool, which in turn can have an effect on the wear on the cutting edge.
\end{abstract}

Mathias Agmell

mathias.agmell@iprod.lth.se

Aylin Ahadi

aylin.ahadi@mek.lth.se

Oleksandr Gutnichenko

oleksandr.gutnichenko@iprod.lth.se

Jan-Eric Ståhl

jan-eric.stahl@iprod.lth.se

1 Department of Mechanical Engineering, Lund University, Lund, Sweden
Keywords Micro-geometry · Finite element analysis · Stress distribution · Turning

\section{Introduction}

In machining processes, the final part surface finish is influenced by changes in tool micro-geometry, chip flow, temperature generation, heat flow and tool wear. The understanding of these interactions during the cutting process is crucial. In fact, this knowledge enables the tool manufactures to evaluate the performance of the cutting tool design prior to manufacturing and expensive field testing. It also enables the users of cutting tools to evaluate the effects of the working conditions on tool life and on the quality of the finished product.

Understanding the metal cutting process is of great importance for the manufacturing industry, since it plays a major role of manufacturing processes such as turning, milling and drilling. The metal cutting operation is a process with large strains up to 1-2 in the primary deformation zone and above 3 in the secondary deformation zone, strain rates up to $10^{6} \mathrm{~s}^{-1}$ and temperatures above $1000{ }^{\circ} \mathrm{C}$ [6]. Due to these extreme conditions present in a cutting process, it is difficult to experimentally measure interesting aspects. The finite element method (FEM) can be used to gain a better understanding of various aspects in the metal cutting process such as cutting forces which has been investigated by many researchers such as $[4,12,16]$ among others. FEM has also been a great asset in studying and understanding the development of the deformation zones and the subsequent temperature effected zones for example by [2, 24, 25]. Residual stresses are also an important aspect in evaluating the integrity of the machined surface and the depth of the deformation hardened layer in the surface which has been 
successfully investigated with FEM by [13, 14, 22]. One area where numerical models are essential is predicting the chip formation process, for example studied by $[8,18]$, a common feature occurring in many materials is segmentation of the chip which for example has been investigated by $[19,36]$. A machining process develops a zone at the contact interface where no displacement occurs in the workpiece material. This is where the workpiece material either flow up into the chip or down into the new surface. The zone is called the stagnation zone, and this phenomenon has been examined by $[13,35]$.

For most of the studies that has used FEM to examine the cutting process, the focus lies on the workpiece material. FEM articles of the machining process that study stress distribution and temperature distribution in the tool are for example [23, 27, 32, 37]. [33] has studied how the friction behaviour at the interaction effect the stress distribution along the rake and flank face. Experimentally, studies that focus on how micro-geometry effect the tool stress has been performed by [7, 11]. In a study performed by [31], a method to predict tool wear based on monitoring of the acceleration and spindle current is proposed. In this present study, the focus will be on the cutting tool. Phenomena that will be examined here are the interaction forces between the cutting tool and workpiece and the stress distribution of the cutting tool in the engagement and stationary phase of a turning operation. The influence the tools micro-geometry has on the stress distribution of the tool at the engagement phase. Also, the effect cutting tools micro-geometry has on the development of the stagnation zone in a cutting process has been studied. The distribution of the tensile and bending stresses is of great importance in cutting tools development. Since the occurrence of crack formation, tool chipping, flaking and breakage is mostly caused by these bending and tensile stresses that the cutting tool experience [28].

The paper is organized as follows: a short description of the machining mechanics is presented in Section 2. The details of the experimental investigation are given in Section 3. In Section 4, the finite element model is presented. The results produced with the model are shown in Section 5. Lastly, Section 6 summarizes the conclusions from this study.

\section{Machining mechanics and theoretical aspects}

The parameters that will be presented in this section are general cutting parameters used to describe an orthogonal cutting process. The uncut chip thickness $h_{1}$ is defined as the uncut thickness of the chip or the distance between the surface prior to machining and the newly formed surface. The cutting speed $v_{c}$ of a machining operation is defined as the relative speed of the workpiece to the cutting edge.
The cutting tool geometry parameters that are present in this article are as follows. The edge radius $r_{\beta}$ is the radius of the edge on the cutting tool, the rake angle $\gamma$ is the angle between a plane perpendicular to the idealized new surface and the rake face of the cutting tool. The clearance angle $\alpha$ is the angle between a plane parallel with the idealized new surface and the clearance face of the cutting tool. The synthetic flank wear $V B_{s}$ which is the length of the surface parallel with the idealized new surface on the clearance face. An illustration of the cutting tool parameters described can be seen in Fig. 1. In addition to these cutting tool parameters, we have the chamfer angel $\gamma_{n}$ and the chamfer length $b_{\gamma_{n}}$ which according to [29] increase the loadingsupporting capacity of the cutting tool. Therefore, chamfers are frequently found on cutting tools used in intermittent cutting.

The resultant force in a turning process can be decomposed into the three orthogonal components. The component acting in the cutting speed direction is referred to as the primary cutting force $F_{c}$; this is usually the largest of the three components. The component acting in the axial feed direction is referred as the feed force $F_{f}$; this is often the second largest force component. The third component acts in the radial feed direction is the smallest of the force components and it is called the passive force $F_{p}$. In the twodimensional case or orthogonal cutting case, the only active forces are the primary cutting force $F_{c}$ and the feed force $F_{f}$.

A machining operation can be divided into three intervals; engagement phase, stationary phase and exit phase. In the engagement phase, the cutting tool and the workpiece get in contact and transient cutting forces occur as the contact pressure increases at the interface. In the stationary phase, a steady-state condition for the cutting forces is achieved; this is the phase where most of the machining takes place in a turning operation. Finally, there is an exit phase where the cutting tool leaves the workpiece in this phase. The cutting forces are also transient as they decrease

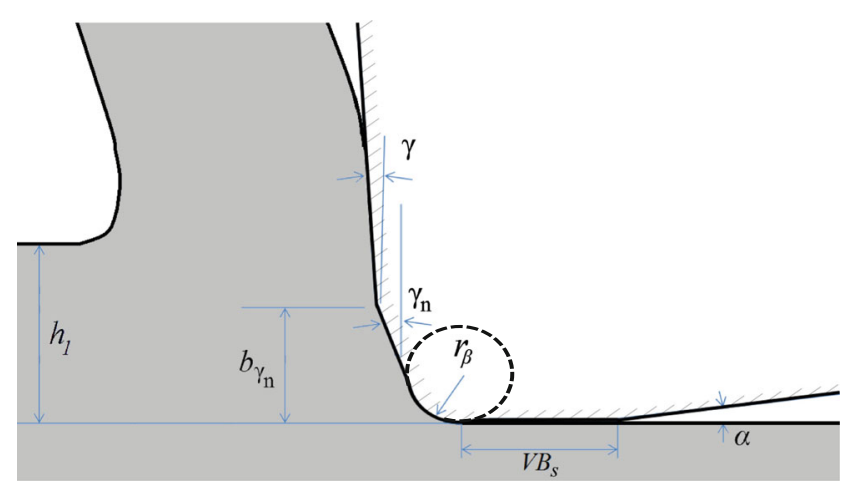

Fig. 1 The basic parameters for a cutting process- and tool geometry parameters 
Fig. 2 The entry phase is shown to the far right, the stationary phase is in the middle and the exit phase is shown to the far left

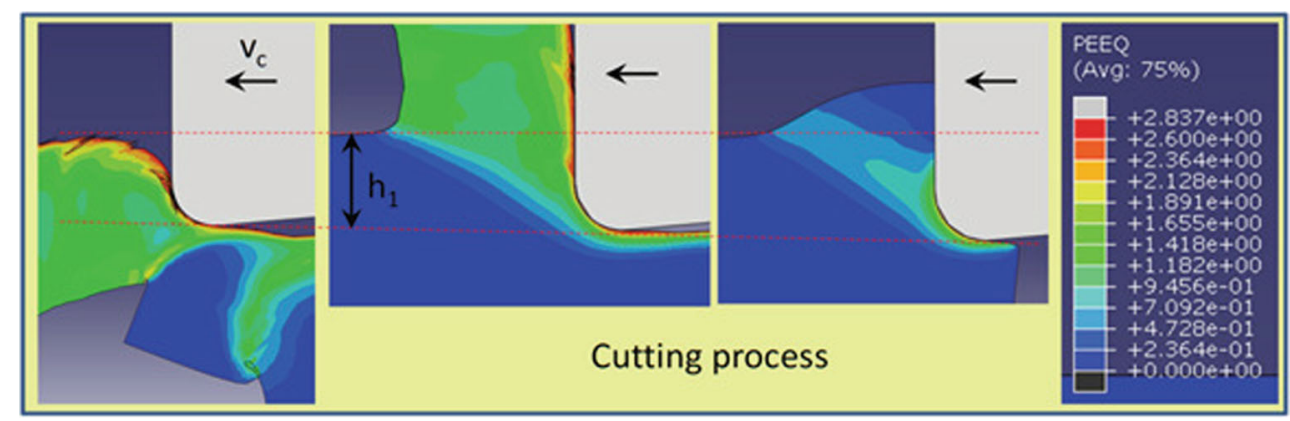

two-dimensional case, the force components $F_{c}$ and $F_{f}$ can be divided according to Eq. 1, where $T_{r}$ and $A_{r}$ are the normal and shearing forces acting on the rake face respectively. $A_{c l}$ and $T_{c l}$ are the normal and shearing forces acting on the clearance face respectively; these are illustrated in Fig. 3.

$$
\begin{aligned}
& F_{c}=T_{r}+T_{c l} \\
& F_{f}=A_{r}+A_{c l}
\end{aligned}
$$

The load function $\varphi_{A T}$ is the relationship of the cutting forces in the $A$ and $T$ direction, according to Eq. 2. This load function should have a strong correlation with the highest principal stress $\sigma_{1}$ in the tool, since a high load in the $T$-direction and a small supporting load in the $A$-direction should start to bend the tool which should produce a high principal stress in the tool. That is, a low value on the load function $\varphi_{A T}$ should give a high principal stress $\sigma_{1}$.

$\varphi_{A T}=\frac{A_{r}+A_{c l}}{T_{r}+T_{c l}}=\frac{F_{f}}{F_{c}}$

In a cutting process, a stagnation zone is produced at the interface between the cutting tool and the workpiece material. Since the workpiece material either has to move toward the rake face of the cutting tool or be ploughed and move toward the clearance face of the cutting tool. Figure 4 shows the schematic relationship between the cutting tool geometry and material stagnation. A portion of workpiece material is pushed upward to the rake face in order to form the chip while another portion is ploughed under the cutting edge to become the machined surface. The stagnation point $P$ is

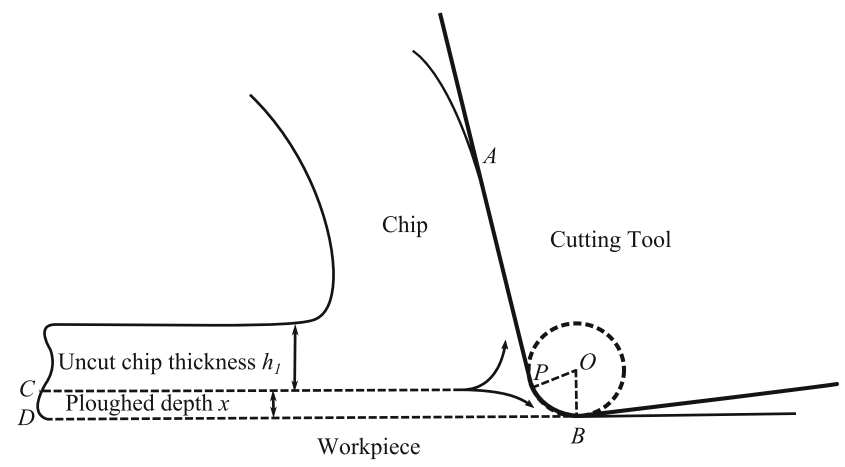

Fig. 4 Schematic view of the stagnation point (not to scale)

Fig. 3 The location of the global maximum principal stress level $\sigma_{1}$, the global maximum effective-stress level $\sigma_{e}$ in $2 \mathrm{D}$ terms during orthogonal cutting and a simplified distribution of the cutting forces $F_{c}$ and $F_{f}$ on the rake and clearance face of the cutting tool 
Fig. 5 The accelerometer sensors inserted into toolholder (a) and experimental setup for the deflection measurements (b)

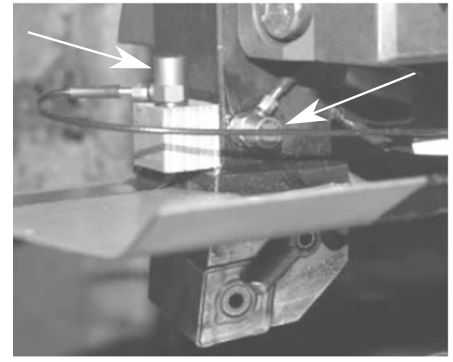

a

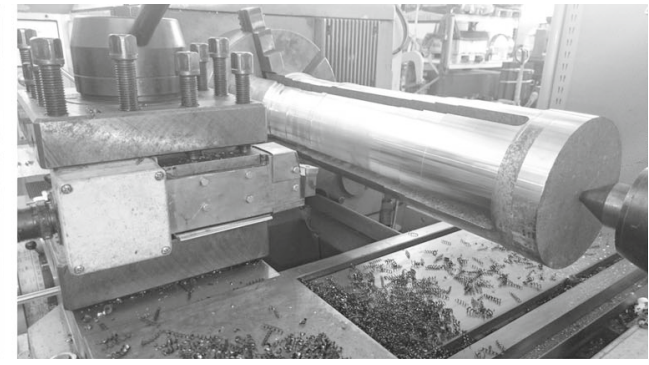

b the location where the material flow separates to form the chip and the machined surface. The chip leaves the tool rake face at point $A$. Point $B$ is the location where the machined surface separates from the tool. $C P$ is the actual material separation line, while $B D$ is the ideal separation line. The ploughed depth $x$ is a small fraction of the uncut chip thickness and represents the amount of material flowing below the cutting edge. At point $P$, a stagnation zone will form where no material displacement will occur; as a result, the shear stresses on the cutting tool will be close to zero in this region, which should have an effect on the wear of the cutting tool around this point $P$.

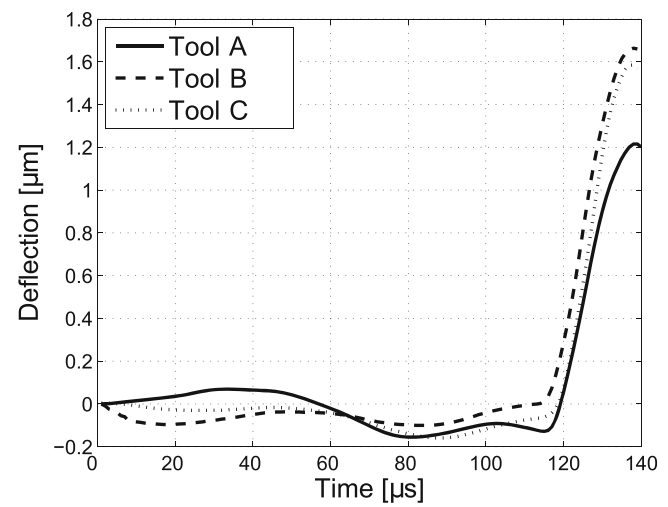

a

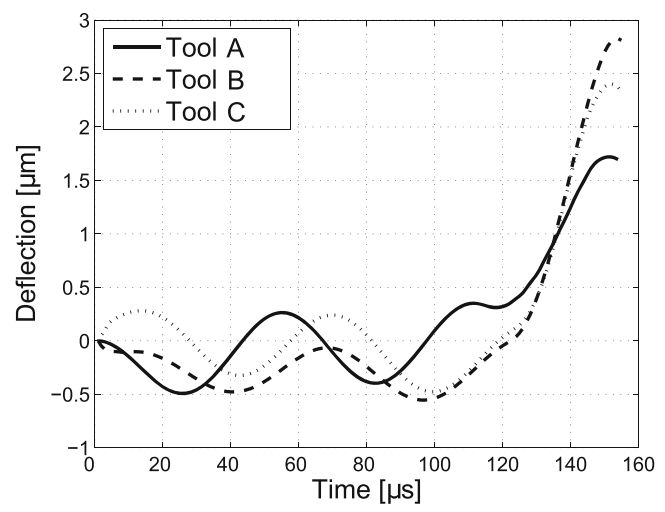

b

Fig. 6 Deflection of the cutting tool at engagement with the workpiece in cutting direction (a) and feed direction (b)

\section{Experimental investigation}

Longitudinal turning tests were performed on a cylindrical bar in order to determine the cutting forces. The workpiece material is a commercial AISI 4140 tempered steel. The forces have been experimentally determined with a stepwise increased feed test in the interval $0.10 \leq h_{1} \leq$ $0.50 \mathrm{~mm}$. The cutting tests were performed in a lathe, Monforts RNC 700 Single Turn. The cutting forces were measured with a cutting force sensor of the fabricate Kistler Z15814. The cutting tool used in the experimental investigations was CNMG120408 MF4 TP2500, Seco Tools AB, with dry cutting conditions. A modified adapter toolholder CTGPL322516, Seco Tools AB, was utilized which gave a rake angel, $\gamma$ of $0^{\circ}$ and a clearance angle, $\alpha$ of $5^{\circ}$. The cutting speed $v_{c}$ was set to $260 \mathrm{~m} / \mathrm{min}$ for all the chip thicknesses. The theoretical chip thickness was then converted to orthogonal cutting conditions using Woxns equivalent chip thickness $h_{e}$, described in [34].

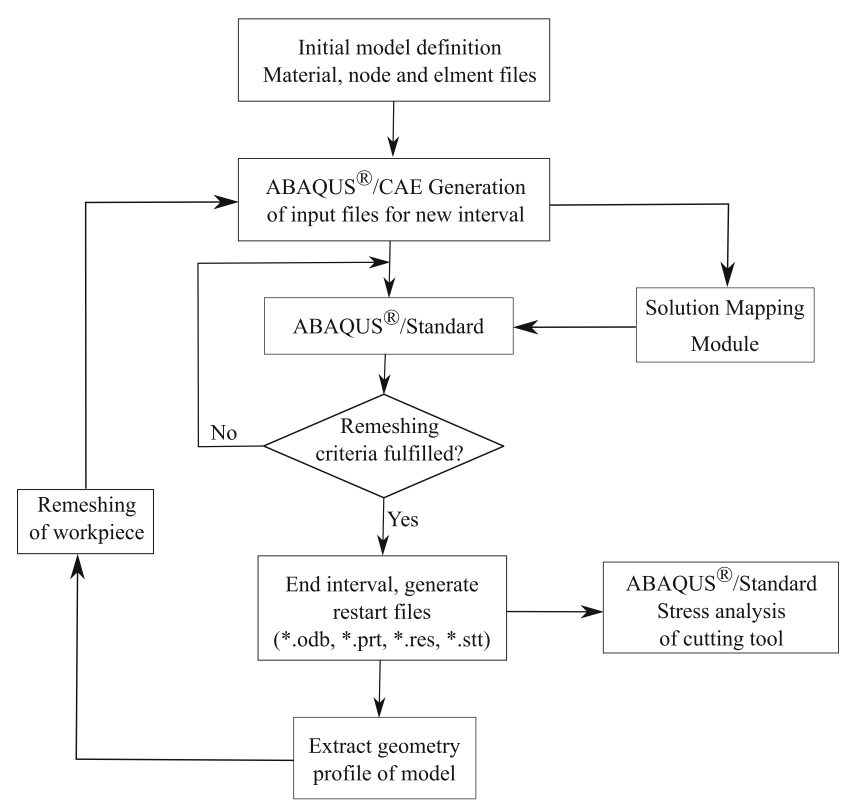

Fig. 7 Overall simulation approach 
Table 1 Johnson-Cook parameters to model the plasticity behaviour of the AISI 4140 [1]

\begin{tabular}{lllll}
\hline$A(\mathrm{MPa})$ & $B(\mathrm{MPa})$ & $C$ & $n$ & $m$ \\
595 & 580 & 0.023 & 0.133 & 1.03 \\
\hline
\end{tabular}

The acceleration of the cutting tool at the engagement has also been experimentally studied in order to verify that the toolholder is not rigid. This will result in that the cutting tool will experience acceleration and motion during the machining operation; this has been analyzed for three cutting tools all with dry cutting conditions. Tool A with no chamfer and no flank wear, DNMG 443-15: VAR.4. Tool B with no chamfer and a synthetic added flank wear of $50 \mu \mathrm{m}$, DNMG 443-15: VAR.5. Tool $\mathrm{C}$ with a chamfer length of $0.1 \mathrm{~mm}$, chamfer angel $-20^{\circ}$ and no flank wear, DNMG 443-15: VAR.2. A modified toolholder with inserted accelerometers which had a sample rate of $10^{6} \mathrm{~Hz}$ was used to collect the acceleration data. The accelerometers inserted on the toolholder can be seen in Fig. 5a. The acceleration signal was sent through a high pass filter and then integrated twice over time in order to determine the deflection of the cutting tool. The cutting speed was set to $260 \mathrm{~m} / \mathrm{min}$ and a feed of $0.3 \mathrm{~mm} / \mathrm{rev}$ was used. The lathe, Boehringer Gppingen VDF where used to perform the cutting tests. The accelerometers where mounted on the toolholder and kept cool in order to cancel out any thermal expansions effects. The modified toolholder and workpiece used for the deflection measurements can be seen in Fig. 5. The deflection for all three tool geometries both for cutting and feed direction can be seen in Fig. 6. These deflections are taken as a mean value of six separate engagements of the cutting tool in the workpiece.

\section{Numerical modelling}

\subsection{Algorithm}

A fully coupled thermo-stress simulation has been performed. The solution technique used in this work is the

Table 2 General thermal and mechanical properties of the modelled materials [1]

\begin{tabular}{llll}
\hline Properties & Workpiece & Tool & Units \\
\hline Density & 7850 & 15,000 & $\mathrm{~kg} / \mathrm{m}^{3}$ \\
Young's modulus & 219 & 540 & $\mathrm{GPa}$ \\
Poisson's ratio & 0.29 & 0.22 & - \\
Thermal expansion & 13.7 & 4.7 & $\mu \mathrm{m} / \mathrm{mK}$ \\
Melting temperature & 1817 & - & $\mathrm{K}$ \\
Bulk temperature & 300 & 300 & $\mathrm{~K}$ \\
Thermal conductivity & 42 & 46 & $\mathrm{~W} / \mathrm{mK}$ \\
Specific heat capacity & - & 203 & $\mathrm{~J} / \mathrm{kgK}$ \\
\hline
\end{tabular}

Table 3 The pressure-dependent heat conduction coefficient [1]

\begin{tabular}{lllllll}
\hline$P(\mathrm{MPa})$ & 0 & 30 & 180 & 300 & 420 & 600 \\
$h\left(\mathrm{~kW} / \mathrm{m}^{2} \mathrm{~K}\right)$ & 5 & 18 & 87 & 222 & 410 & 500 \\
\hline
\end{tabular}

Updated-Lagrangian method; this is a common strategy to solve problems involved with large deformations. The workpiece was remeshed in predefined intervals by an in-house Python script. Afterwards, the old solution data (local material parameters like plastic strains, temperatures, etc.) are interpolated onto the new mesh with the function *MAP SOLUTION.

The finite element analysis is divided into two steps. The first step is a fully coupled thermal-stress simulation where the workpiece is considered an elasto-viscoplastic material according to the material model described in Subsection 4.2. In this first step is where the actual machining simulation is performed; here, the tool is modelled as a rigid body. The second step is based on the interaction force acting on the rigid tool from the workpiece in the machining simulation. These interaction forces are then applied to the tool as boundary conditions, and a stress analysis is performed where the tool is considered as a linear elastic material. It is in this second step where the determination of the maximal principal stress, $\sigma_{1}$ and maximum effective stress, $\sigma_{e}$ in the tool is achieved. A schematic illustration of the remeshing method and the overall simulation approach used in this study can be seen in Fig. 7.

\subsection{Material model}

In a machining process, the workpiece material is exposed to high levels of strain, strain rate and temperature. Therefore, it is important to add these dependencies into the material model to accurately describing the flow stress of the material. For this reason, the Johnson-Cook plasticity model is used in this study, developed by Johnson and
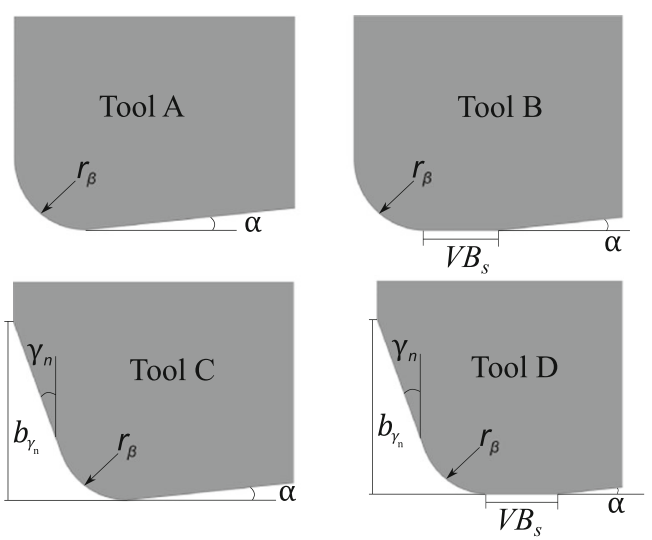

Fig. 8 The micro-geometries of the four tools in the FEM model 


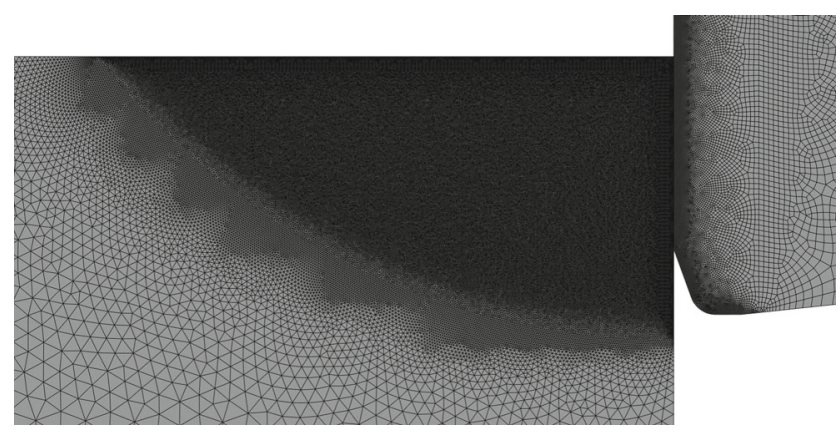

Fig. 9 Initial element configuration in the deformation zone, of the simulation with Tool D

Cook in [17]. This constitutive relationship is commonly employed when modelling orthogonal cutting with use of FEM, such as $[3,5,9,22,36]$. The Johnson-Cook constitutive law is presented in Eq. 3, where $\bar{\sigma}$ is the equivalent stress, $\bar{\varepsilon}$ is the equivalent plastic strain, $\dot{\bar{\varepsilon}}$ is the equivalent plastic strain rate, $\dot{\bar{\varepsilon}}_{0}$ is the reference strain rate, $A$ is the initial yield stress, $B$ is the hardening modulus, $C$ is the strain rate dependency coefficient, $n$ is the strain-hardening exponent, $m$ is the thermal softening coefficient, $\theta$ is the process temperature, $\theta_{m}$ is the melting temperature and $\theta_{0}$ is the bulk temperature of the workpiece.

$\bar{\sigma}=\left[A+B \bar{\varepsilon}^{n}\right]\left[1+C \ln \left(\frac{\dot{\bar{\varepsilon}}}{\dot{\bar{\varepsilon}}}\right)\right]\left[1-\left(\frac{\theta-\theta_{0}}{\theta_{m}-\theta_{0}}\right)^{m}\right]$

The workpiece was considered to consist of a AISI 4140 steel and the cutting tool was modelled as cemented carbide material. The Johnson-Cook parameter values used to simulate the behaviour of the AISI 4140 workpiece are specified in Table 1. The specific heat of the workpiece material is highly temperature dependent since the material undergoes a phase change at about $1000 \mathrm{~K}$. Therefore,

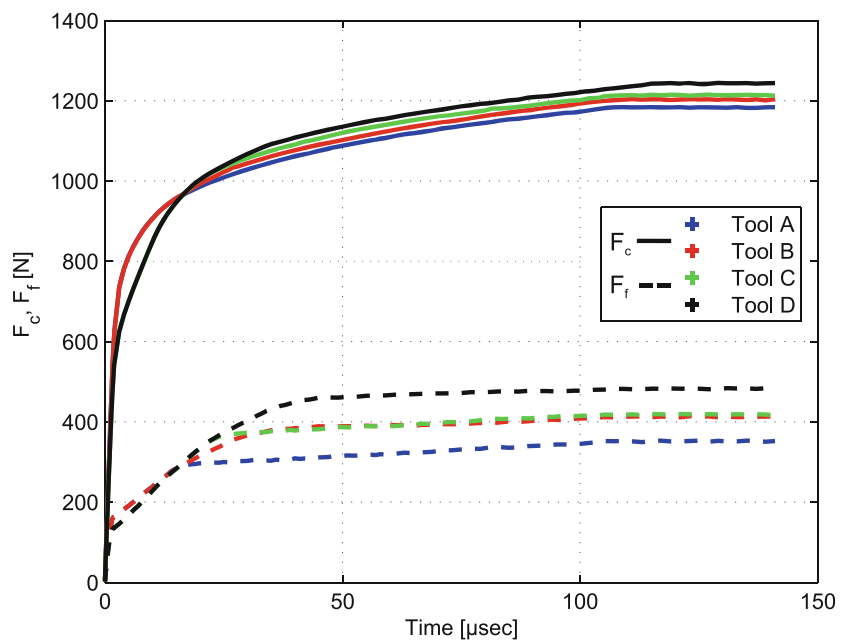

Fig. 10 Primary cutting force and feed force as a function of time in the engagement phase
Table 4 Correlation between simulated and experimental static primary cutting force $F_{c}$ and static feed force $F_{f}$

\begin{tabular}{lrlll}
\hline & \multicolumn{2}{c}{$F_{c}[\mathrm{~N}]$} & \multicolumn{2}{c}{$F_{f}[\mathrm{~N}]$} \\
$h_{1}(\mathrm{~mm})$ & \multicolumn{1}{l}{$\operatorname{Sim}$} & $\operatorname{Exp}$ & $\operatorname{Sim}$ & \multicolumn{1}{l}{$\operatorname{Exp}$} \\
\hline 0.1 & 299.2 & $300.4 \pm 1.7$ & 166.3 & $172.0 \pm 0.9$ \\
0.2 & 556.1 & $524.9 \pm 2.6$ & 217.0 & $222.3 \pm 1.8$ \\
0.3 & 802.5 & $749.3 \pm 6.7$ & 276.1 & $272.7 \pm 6.6$ \\
0.4 & 1044.1 & $973 . \pm 13.5$ & 341.2 & $323.0 \pm 11.7$ \\
0.5 & 1183.4 & $1198 \pm 17.4$ & 351.9 & $373.3 \pm 14.6$ \\
\hline
\end{tabular}

a temperature-dependent specific heat capacity is utilized for the workpiece according to [1]. The general thermal and mechanical properties of the workpiece and the cutting tool are presented in Table 2.

There are two sources of heat generation in the machining material: plastic deformation and friction. Most of the plastic deformation energy is converted to heat. In the present study, the percentage was taken as $90 \%$; this has been used in previous studies such as [21, 26]. Since the heat generated by friction is assumed to be fully absorbed by the material, the fraction of the heat generated by friction is set to 1.0. This has been used in previous studies such as $[3,26]$. In simulating the heat flow between the tool and the workpiece, a thermal boundary condition was defined. The heat conduction between the tool and the workpiece is pressure-dependent. The heat conduction coefficient $h$ is defined as a function of the pressure in accordance with Table 3. The conductive heat transfer between the contact surfaces is defined in Eq. 4, where $\mathrm{q}$ is the heat flux per unit of area crossing the interface from point $X$ on the one surface to point $Y$ on the other, $\theta_{X}$ and $\theta_{Y}$ being the temperatures of the points on the surfaces and $h(P)$ being the heat conduction coefficient.

$q=h(P)\left(\theta_{X}-\theta_{Y}\right)$

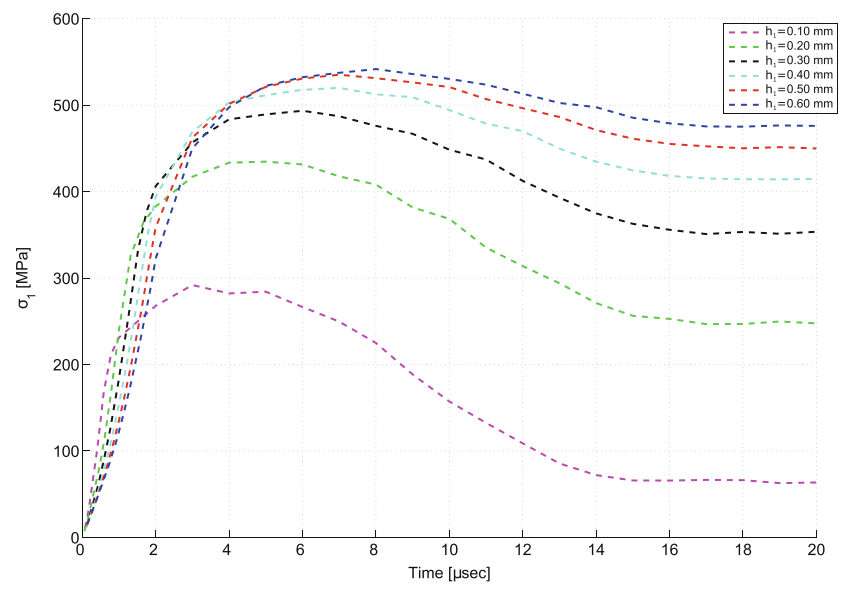

Fig. 11 Maximum principal stress, $\sigma_{1}$ in cutting tool A, for theoretical chip thicknesses $h_{1}=0.10-0.60 \mathrm{~mm}$, as a function of time 


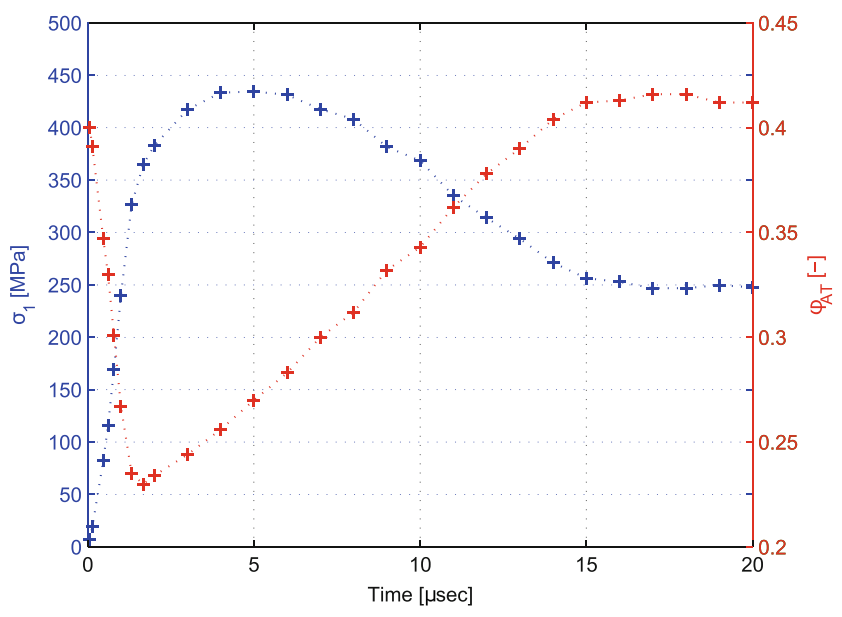

a

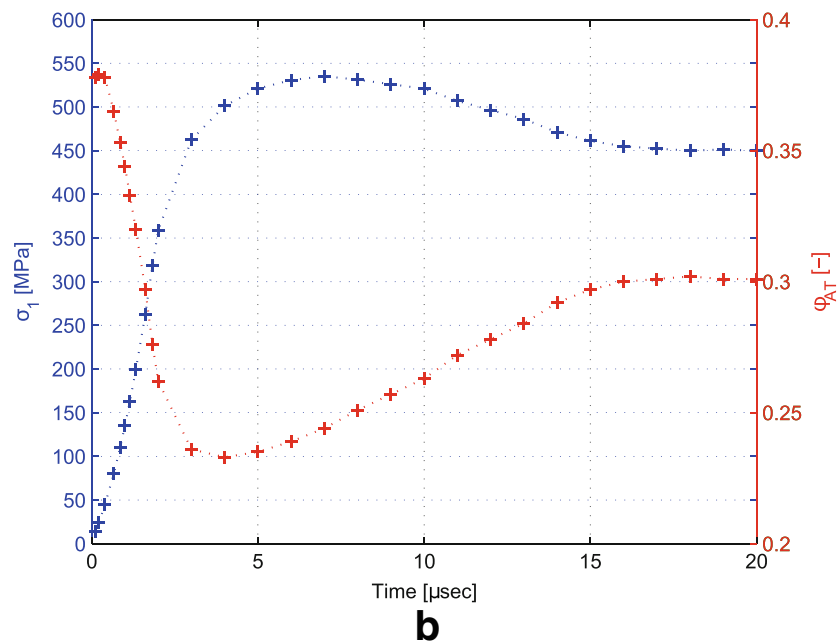

Fig. 12 Maximal principal stress, $\sigma_{1}$ and load function, $\varphi_{A T}$ as a function of time in tool A, for $h_{1}=0.20 \mathrm{~mm} \mathrm{(a)} \mathrm{and} 0.5 \mathrm{~mm} \mathrm{(b)}$

\subsection{Interaction modelling}

The interaction in a turning process can be divided into three zones with different tribological properties, according to [15]. These are a sticking zone, an adhesion zone and a sliding zone. The sticking zone is apparent at high pressures as around the tool tip, at low contact pressure sliding friction is occurring and in the transition between these two zones is where the adhesion behaviour is found.

In this report, the combination of the Coulomb's and shear friction model has been used, see Eq. 5, where $\tau_{f}$ is the frictional stress, $\mu$ is the fiction coefficient, $\sigma_{n}$ is the normal stress and $\tau_{y}$ is the shear strength of the workpiece, which is defined as $\tau_{y}=\sigma_{y} / \sqrt{3}$ where $\sigma_{y}$ is the uniaxial yield stress. The reason this model is used is that the mechanism behind the frictional behaviour is not fully understood; therefore, this model has been used for reason of simplicity. This model has been used in many earlier studies for
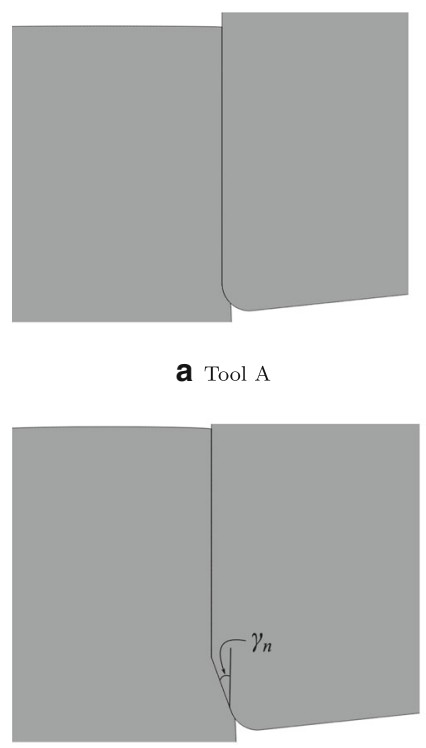

C Tool C a $\operatorname{Tool} \mathrm{A}$

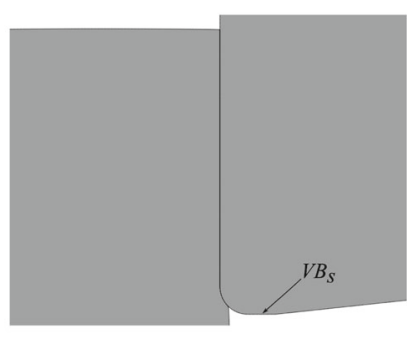

b Tool B

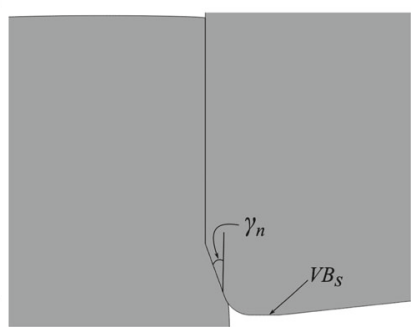

d Tool D
Fig. 13 The interaction between the tool and the workpiece that gives the peak in the maximal principal stress $\sigma_{1}$, when $h_{1}=0.50 \mathrm{~mm}$

example [3, 10, 20, 21].

$\tau_{f}=\min \left(\mu \sigma_{n}, \tau_{y}\right)$

\subsection{Computational parameters}

The orthogonal cutting process was simulated using a $2 \mathrm{D}$ model in ABAQUS/Standard v6.12-3. The workpiece length was taken to $5 \mathrm{~mm}$ and its height to $2 \mathrm{~mm}$. The uncut chip thickness, $h_{1}$ varies from 0.1 to $0.6 \mathrm{~mm}$ in intervals of $0.1 \mathrm{~mm}$. The same cutting speed as in the experimental study has been used for all of the simulations. Four different tools has been used in this work where tool A had a rake angle $\gamma$ of $0^{\circ}$, clearance angle $\alpha$ of $5^{\circ}$, an edge radius $r_{\beta}$ $50 \mu \mathrm{m}$ and no flank wear. Tool B had the same tool geometry as tool A but with the exception it has a synthetic flank wear $V B_{s}$ of $50 \mu \mathrm{m}$. Tool $\mathrm{C}$ had had a rake angle $\gamma$ of $0^{\circ}$, clearance angle $\alpha$ of $5^{\circ}$, an edge radius $r_{\beta} 50 \mu \mathrm{m}$, a chamfer angel $\gamma_{n}$ of $-20^{\circ}$ and a chamfer length $b_{\gamma_{n}}$ of $125 \mu \mathrm{m}$. Tool D had the same tool geometry as tool $\mathrm{C}$ but with the exception it has a synthetic flank wear $V B_{s}$ of $50 \mu \mathrm{m}$. The width has been set to $3.2 \mathrm{~mm}$ for all of the tools; the tool micro-geometry for the four tools can be seen in Fig. 8.

The number of elements in the simulation is variable as it increases with both the theoretical chip thickness $h_{1}$ and as the tool progresses into the workpiece. For the simulation where $h_{1}$ is set to $0.50 \mathrm{~mm}$ and cutting tool one is used, there are about 102,000 elements and 51,000 nodes were used at the beginning of the simulation and 251,000 elements and 126,000 nodes near the end of the analysis. Figure 9 shows the initial element configuration of the simulation with tool 
Fig. 14 The stress distribution in the cutting tools, when the maximal principal stress peaks, when $h_{1}=0.50 \mathrm{~mm}$

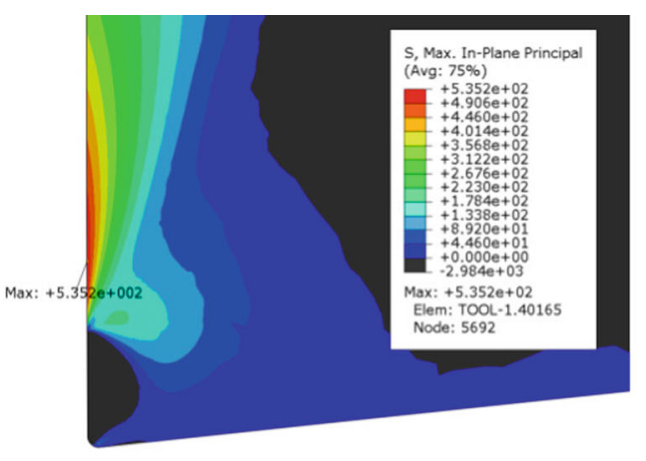

a Tool $\mathrm{A}$

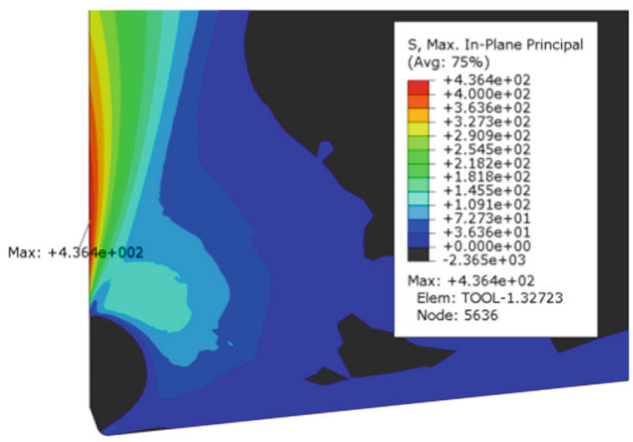

c Tool C

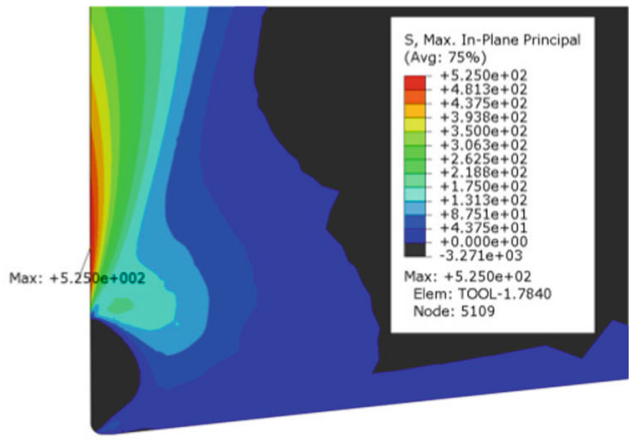

b Tool B

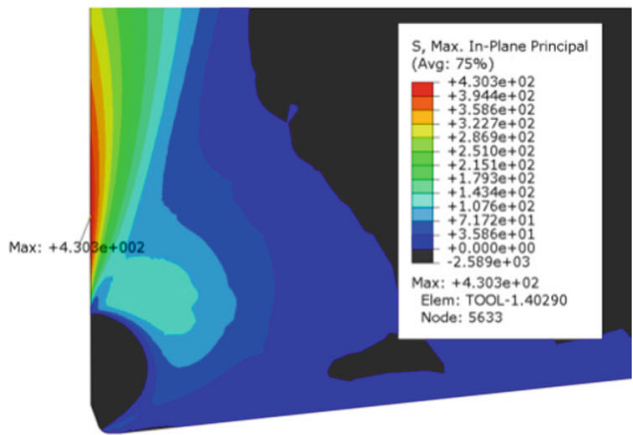

d Tool D
D. The element edge length was about $2 \mu \mathrm{m}$ in the shear zone. The computing time needed for the machining simulation is about 3 days. The subsequent stress analysis of the tool takes about $2 \mathrm{~min}$, on a workstation with an i7 intel processor and a memory of $16 \mathrm{~GB}$. The elements used in the workpiece were a triangular element called CPE3T in Abaqus/Standard which is a 3-node plane strain thermally coupled triangle, linear displacement and temperature. The elements used for the tools were a brick element which has the code CPE4T in Abaqus/Standard; this is a 4-node plane strain thermally coupled quadrilateral, bilinear displacement and temperature.

\section{Results}

In the first subsection of the results part, the simulated cutting forces in the stationary phase are compared with experimental data; this is done for tool $\mathrm{A}$, since it has the same micro-geometry as the insert CNMG120408 MF4 TP2500 which was used in the experimental investigations for the cutting forces. Also, the simulated cutting forces at the engagement phase are presented for all of the different tool micro-geometries. In Subsection 5.2, the maximal principal stress in the cutting tool at the engagement phase is presented. Subsection 5.3 investigates the effect the shear stresses at the interface have on the maximal principal stress in the tool. Subsection 5.4 covers the influence the microgeometry of the tool has on the stagnation zone. Finally, Subsection 5.5 presents the effective stress in the tools and its dependence of the different micro-geometries.

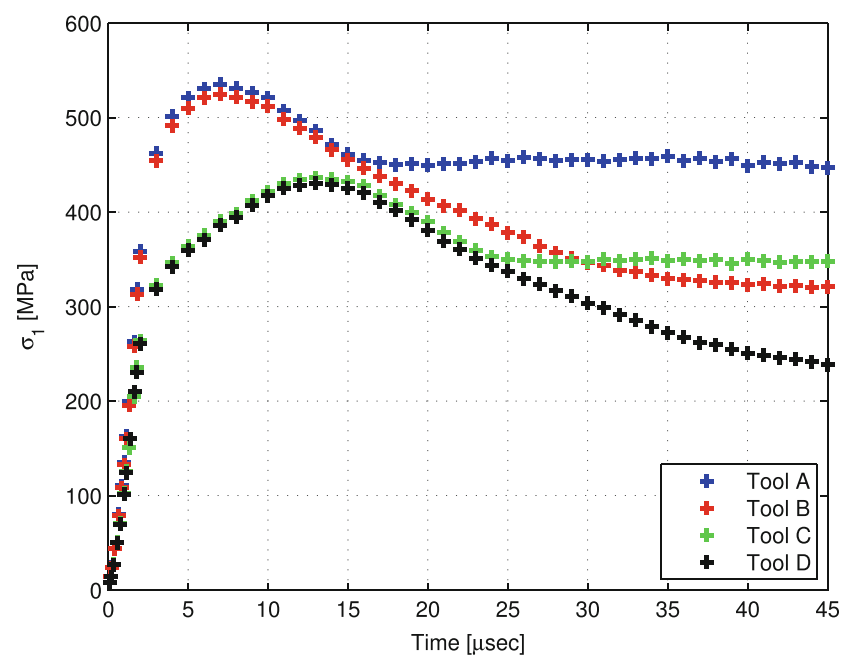

Fig. 15 Maximal principal stress, $\sigma_{1}$ as a function of time for all four micro-geometries, when $h_{1}=0.50 \mathrm{~mm}$ 


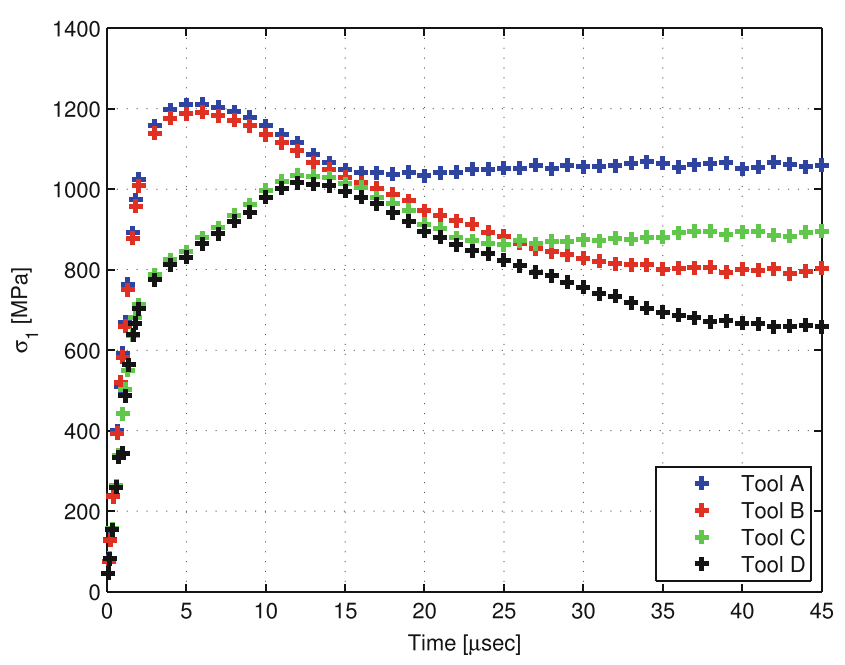

Fig. 16 Maximal principal stress, $\sigma_{1}$ as a function of time for all four micro-geometries when shear forces are neglected. All simulations are done with $h_{1}=0.50 \mathrm{~mm}$

\subsection{Cutting forces}

In order to compare the experimental and simulated cutting forces. The theoretical chip thickness has been converted to orthogonal cutting using Woxns equivalent chip thickness $h_{e}$, described in [34]. The validation of the cutting forces in terms of comparison of the simulated forces with experimental are done in the stationary phase. In Table 4, the correlation between the simulated and experimental cutting forces is presented. In Fig. 10, the simulated cutting forces as a function of time for all four micro-geometries is presented; this figure illustrates force build-up in the engagement phase and the beginning of the stationary phase. As seen in Table 4, good agreement is obtained between the simulated and experimental values for both the primary cutting force and the feed force. This indicates that the FEM model can produce reliable results for contact forces between the cutting tool and the workpiece.

\subsection{Maximal principal stress with shear forces}

In this section, the effect of the theoretical chip thickness has on the maximal principal stress is presented. The stress distribution at which the maximal principal stress reaches its maximum are also illustrated. In Fig. 11, the maximal principal stress in tool A as a function of time is shown. It can be seen that the maximal principal stress increases with the theoretical chip thickness. The maximal principal stress rapidly increases until it reaches its peak value. This peak value occurs just before the cutting tool gains support at the clearance face by the workpiece. This support introduces normal forces at the clearance face that counter the normal forces at the rake face, which leads to a decrease of the maximal principal stress. Figure 13a illustrates the contact between tool $\mathrm{A}$ and the workpiece at which the peak occurs in the maximal principal stress in tool $\mathrm{A}$, when $h_{1}=0.50$
Fig. 17 The stress distribution in the cutting tools with neglected shear forces, when the maximal principal stress peaks. All simulations are done with $h_{1}=0.50 \mathrm{~mm}$

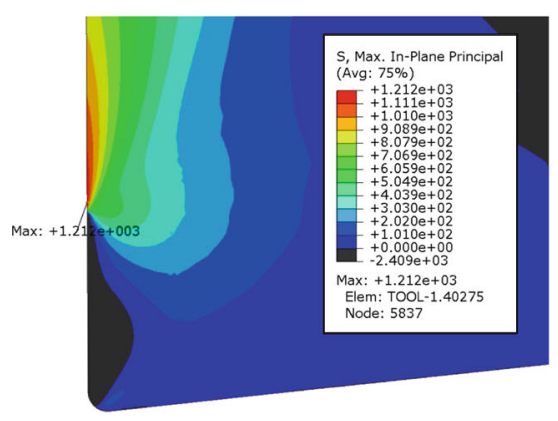

a Tool A

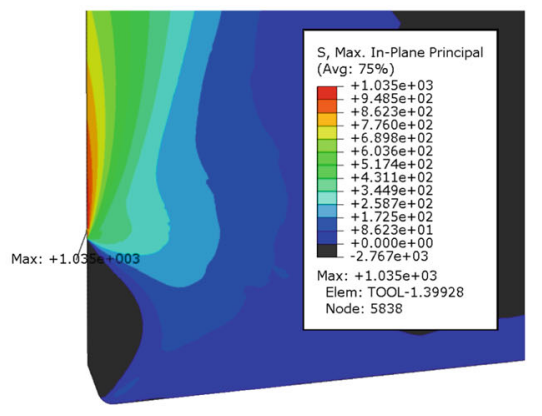

c Tool C

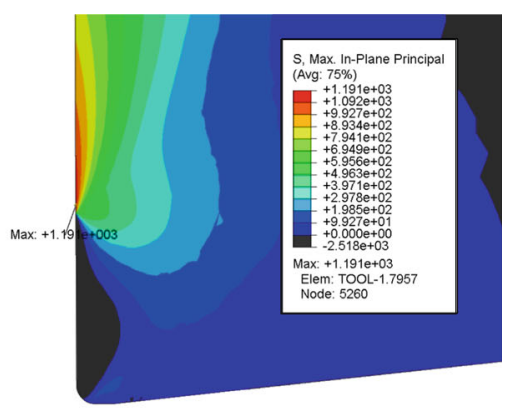

b Tool B

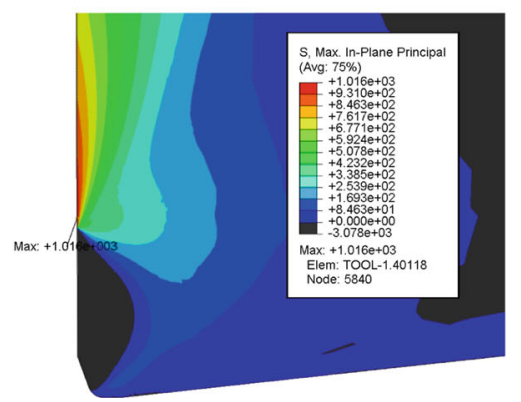

d Tool D 
Fig. 18 The magnitude of the shear forces acting on tool A, at time $45 \mu \mathrm{s}$. This indicates that a stagnation zone have been developed in the cutting process

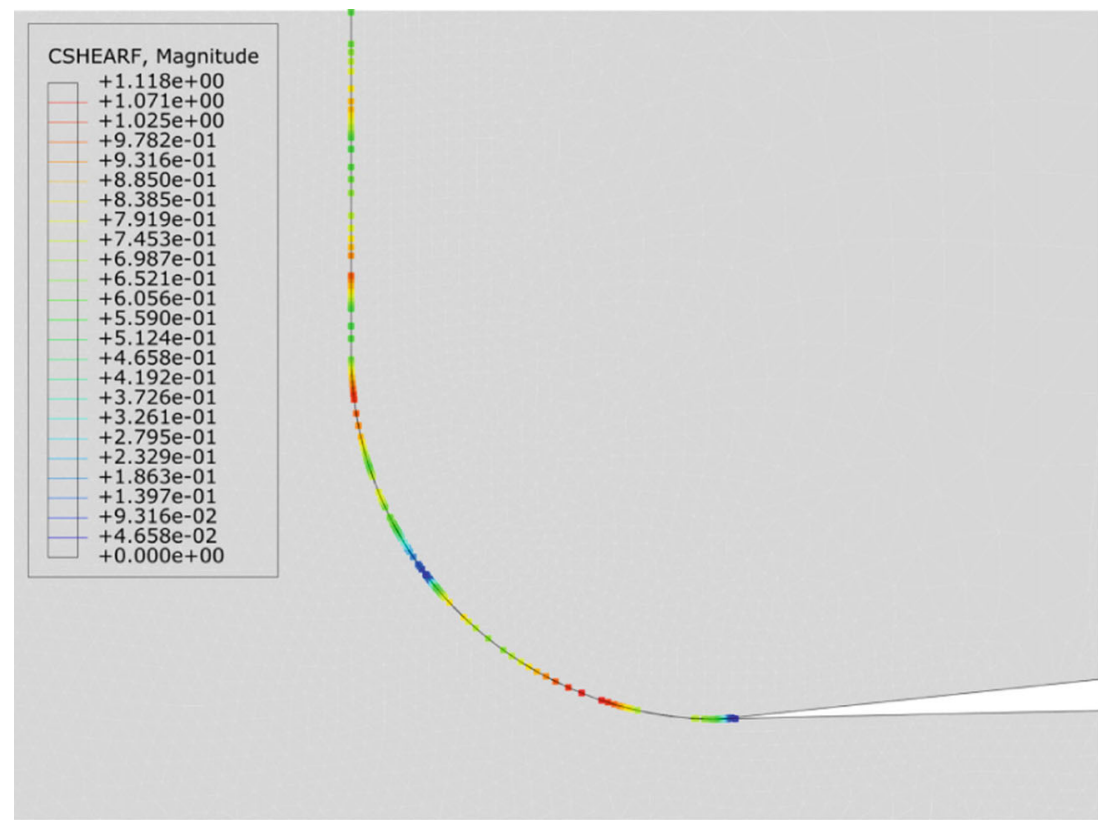

$\mathrm{mm}$. Figure 14a shows the stress distribution in cutting tool $A$ at which the peak value of the maximal principal stress is achieved, when $h_{1}=0.50 \mathrm{~mm}$. As mentioned in Section 2, the load function $\varphi_{A T}$ has a strong correlation with the maximal principal stress $\sigma_{1}$. Since a high load in the $T$-direction and small supporting load in the $A$-direction should start to bend the tool which should produce a high principal stress $\sigma_{1}$ in the tool. As seen in Fig. 12, the load function $\varphi_{A T}$ in tool A develops a minimum just before the peak value of the maximal principal stress $\sigma_{1}$ occurs. This indicates that the FEM model is able to correctly capture this phenomenon.

The effect the micro-geometry for tool B, tool C and tool $\mathrm{D}$ has on the stress distribution is also investigated. The maximal principal stress as a function of time for all the cutting tools is shown in Fig. 15 when the theoretical chip thickness is equal to $0.5 \mathrm{~mm}$. For tool C and D, the peak value decrease; this shows that micro-geometries with a positive chamfer angle reduce of the maximal principal stress
Fig. 19 The magnitude of the displacement of the workpiece material, illustrating the formation of a stagnation zone at the contact interface

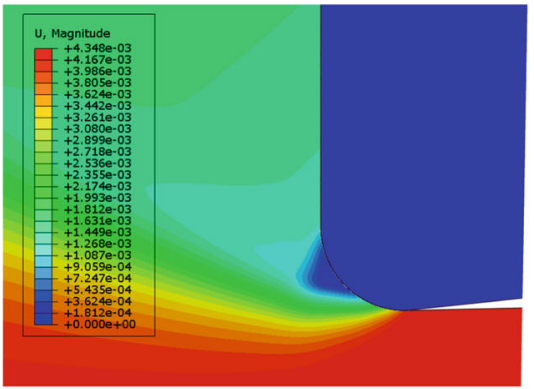

a Tool A

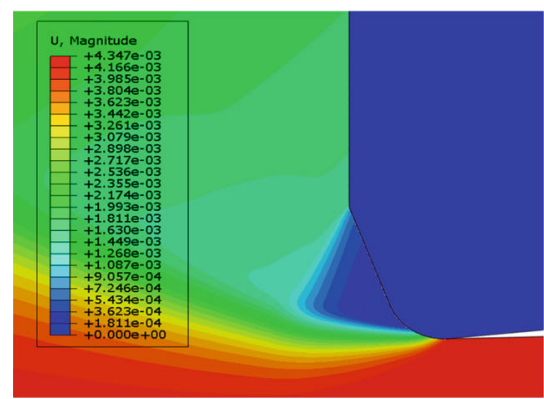

c Tool C

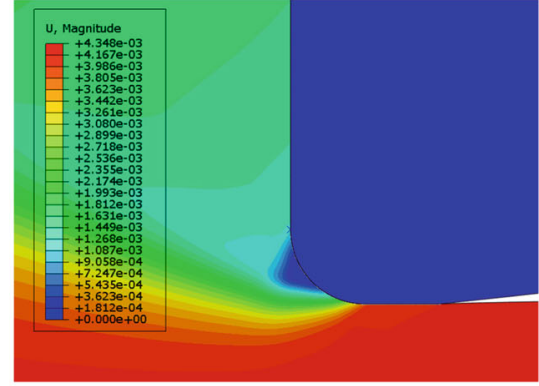

b Tool B

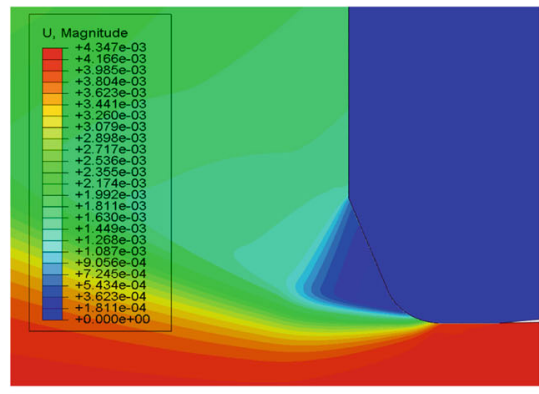

d Tool D 


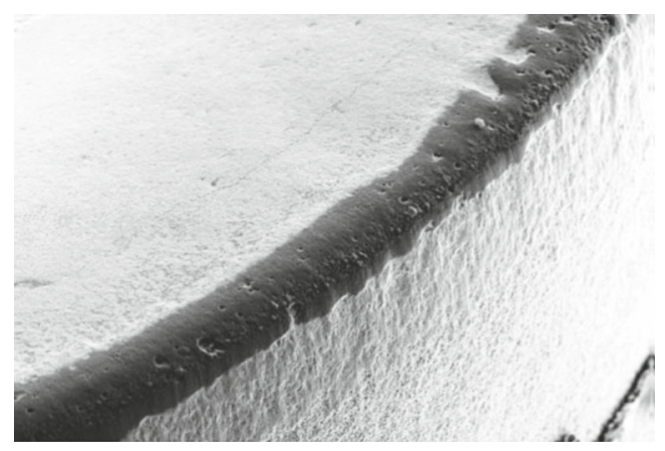

Fig. 20 Experimental visualization of the stagnation zone, due to the obtained tool wear

at the engagement phase. It can also be seen that the peak value is achieved later than for tool $\mathrm{A}$ and $\mathrm{B}$. The reason for this is that the chamfer in tool C and D has to be fully in contact with the workpiece before the edge radius of the tool comes in contact; this is where the peak value of the maximal principal stress is reached. The interaction between tool and the workpiece where the maximal principal stress peaks can be seen in Fig. 13. A minor reduction of the peak value of the maximal principal stress is also achieved with synthetic flank wear present on the tool, which is the only difference between tool $\mathrm{A}$ and $\mathrm{B}$. It can also be seen that tool $\mathrm{B}$ and $\mathrm{D}$ has a lower maximal principal stress at the stationary phase. The reason for this is that these tools have a greater contact area at the clearance face due to the synthetic flank wear. This increase the force at the clearance face which counters the force at the rake face leading to a lower maximal principal stress in the tool. The stress distribution at which the maximal principal stress peaks in all the four micro-geometries is shown in Fig. 14.

\subsection{Maximal principal stress without shear forces}

In this subsection, a stress analysis similar to the one in Subsection 5.2 is presented; the differences is that in this part the shear forces of the contact forces is neglected. The reason for this is that all principal stresses in Section 5.2 are low in comparison to what the actual tool material is able to handle according to experimental tests. As seen in experimental investigation in Section 3, the tool undergoes acceleration in the engagement phase; this leads to a motion of the tool surface at the contact zone. This movement of the tool will reduce the shear forces acting at the contact interface. This means that the shear forces will change direction during the engagement phase and fluctuate around zero, which in turn implies that the shear forces will be drastically reduced during this stage. As a result, a FEM stress analysis of the tools with only normal forces active has been performed. In order to investigate how this effect the maximal principal stresses in the different tool micro-geometries.

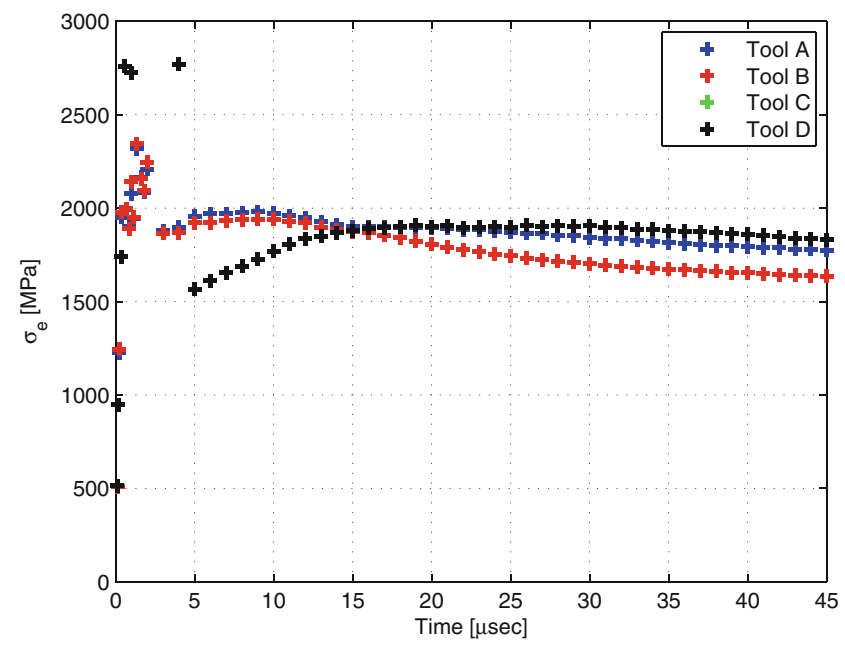

Fig. 21 Maximum effective stress, $\sigma_{e}$ as a function of time for all four micro-geometries, when $h_{1}=0.50 \mathrm{~mm}$

All of the simulations in this section are done with the theoretical chip thickness equal to $0.50 \mathrm{~mm}$. In Fig. 16, the maximal principal stress for all the four cutting tools as a function of time is presented. It can be seen that the shear forces has a major influence on the magnitude of the maximal principal stress in the tool. When the shear forces are neglected, the peak values of the maximal principal stress are in the region of surface flexural strength of the raw sintered cemented carbide tool material, which would lead to a tool failure according to [30]. The curve where the shear forces are neglected can be serving as an upper bound and the curve with shear forces active a lower bound of the maximal principal stress in a real turning process. In Fig. 17, the stress distribution of all the cutting tools is shown. It can be seen that the shear forces do not have a sizable effect of the actual distribution of the maximal principal stress, compared with Fig. 14. It only has a major effect of the magnitude of the distribution.

\subsection{Stagnation zone}

The stagnation zone can have a drastic effect on the wear of the tool, since where the stagnation zone forms no net motion between the cutting tool and the workpiece is present. This should reduce the wear of the cutting tool since the stagnation zone in the workpiece material will act as a protective layer to the cutting edge. The presence of the stagnation zone leads to a drastic reduction of the shear forces at the interface between the cutting tool and the workpiece since no motion at the contact surface is present. Figure 18 shows the shear forces at the contact interface for cutting tool A. As seen in Fig. 18, there is an area where the shear forces indicate that a stagnation zone is present in the process. Another way to illustrate the stagnation zone is 
Fig. 22 The stress distribution of the effective stress at time $20 \mu$ s for all the four micro-geometries, when $h_{1}=0.50 \mathrm{~mm}$

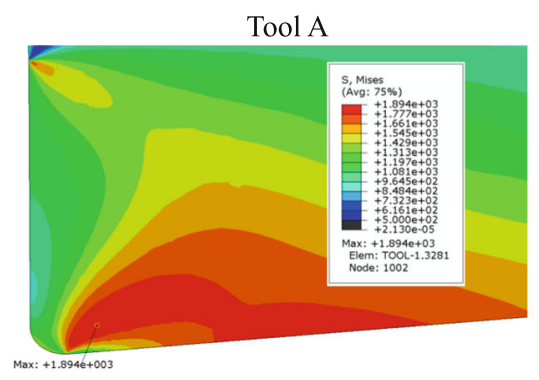

a Tool A

Tool C

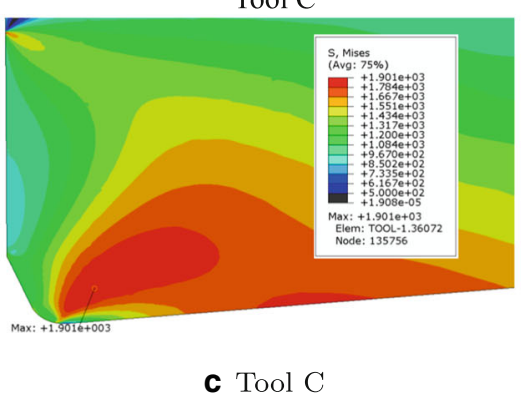

Tool B

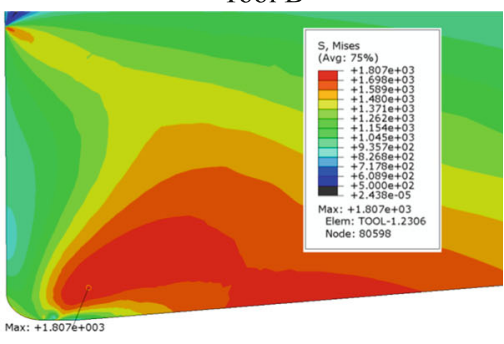

b Tool B

Tool D

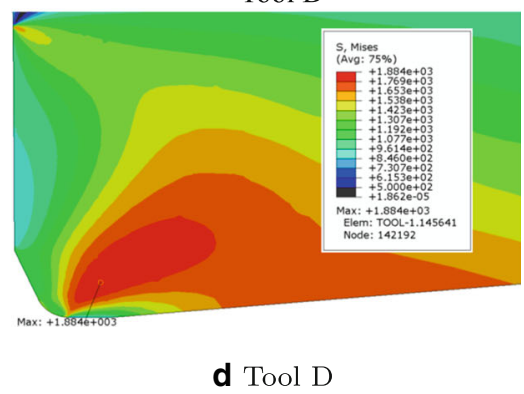

to monitor the displacements in the workpiece. At a stagnation zone, the motion of the workpiece material should be close to zero, leading to an area with very low displacement. Figure 19 shows the displacement of the workpiece material for all four micro-geometries. An observation is that Fig. 19c, d which are the tools with a chamfer has a bigger stagnation zone, which in turn should lead to lower wear of cutting tools of this type micro-geometry. In Fig. 20, an actual cutting insert is shown where the wear on the tool is significantly lower at the edge radius. This indicates that a stagnation zone was formed at the edge radius of the insert. This cutting insert has similar geometrical shape as cutting tool A in this study, which verifies that the FEM model is able to simulate the formation of the stagnation zone of a turning process correctly.

\subsection{Maximum effective-stress}

In this subsection, the effective stress in the cutting tool is investigated. It has been performed for all four microgeometries in order to determine the impact it has on the effective stress of a cutting tool in a turning process. In Fig. 21 , the maximum effective stress in the cutting tool as a function of time is presented. It can be seen that the maximum effective stress does not have a peak value such as the maximal principal stress; instead, it rapidly increases and then reaches a stable value just after the initial contact with the workpiece. The cutting tool geometries do not have a major influence on the maximum effective stress after about $5 \mu \mathrm{s}$; all micro-geometries experience an effective stress value of about $1650-1900 \mathrm{MPa}$. For tool C and D, the effective stress peak at around $9000 \mathrm{MPa}$ in the interval 0 to $5 \mu \mathrm{s}$. This is caused by numerical effects, when the sharp edge that occurs when the rake angle changes from 0 to $-20^{\circ}$ makes contact with the workpiece material. The maximum effective stress as a function of time in tool C and tool D is almost identical, as results in that the black data points of tool D overlaps the green data points of tool C in Fig. 21. The stress distributions of the effective stress in all the tools at the time $20 \mu$ s are shown in Fig. 22.

\section{Conclusions}

The effect of the cutting edge micro-geometry on stress distribution plays an important role in cutting processes. This study has shown that the micro-geometry can reduce the maximal principal stress in the tool for both the engagement and stationary phase. The result indicates that the tool with a chamfer decrease the maximal principal stress by about $20 \%$ in the engagement phase. Tools with a synthetic flank wear will reduce the maximal principal stress about $30 \%$ in the stationary phase. These observations indicate that tools with a micro-geometry with both a synthetic flank wear and a chamfer are beneficial geometry features in controlling stresses experienced by the tool that could lead to failure. Optimizing the micro-geometry of the tool could have a major impact on machining operations with several engagements such as intermittent turning and milling operations. The reason that a chamfer effectively reduces the 
maximal principal stress in the engagement phase is that the normal forces acting at the chamfer counters the bending of the tool along the axis perpendicular to the simulated plane. Although both a chamfer and a synthetic flank wear could increase the principal stress of the tool in the exit phase, since here the workpiece will try to bend the tool in the opposite direction along the axis perpendicular to the simulated plane.

The FEM model and experimental results also indicates that tools with a chamfer generate a larger stagnation zone at the contact interface, which will reduce the tool wear in this area. For tools with a chamfer, the stagnation zone is moved up along the rake face. This leads to that a larger portion of the workpiece will flow into the machined surface which should increase the size of the deformation hardened layer produced by the machining operation.

Acknowledgments This work was co-funded by the European Union's Horizon 2020 Research and Innovation Programme under Flintstone2020 project (grant agreement No 689279). It is also a part of the strategic research program of the Sustainable Production Initiative SPI, involving cooperation between Lund University and Chalmers University of Technology.

Open Access This article is distributed under the terms of the Creative Commons Attribution 4.0 International License (http:// creativecommons.org/licenses/by/4.0/), which permits unrestricted use, distribution, and reproduction in any medium, provided you give appropriate credit to the original author(s) and the source, provide a link to the Creative Commons license, and indicate if changes were made.

\section{References}

1. Agmell M, Ahadi A, Ståhl JE (2011a) A fully coupled thermomechanical two-dimensional simulation model for orthogonal cutting: formulation and simulation. Proc Instit Mech Eng Part B: J Eng Manuf 225(10):1735-1745

2. Agmell M, Ahadi A, Ståhl JE (2011b) A numerical and experimental investigation of the deformation zones and the corresponding cutting forces in orthogonal cutting. In: Advanced Materials Research, vol 223. Transmission Technology Publishing, pp 152161

3. Akbar F, Mativenga PT, Sheikh M (2010) An experimental and coupled thermo-mechanical finite element study of heat partition effects in machining. Int J Adv Manuf Technol 46(5-8):491-507

4. Arola D, Ramulu M (1997) Orthogonal cutting of fiber-reinforced composites: a finite element analysis. Int J Mech Sci 39(5):597613

5. Arrazola PJ et al (2010) Investigations on the effects of friction modeling in finite element simulation of machining. Int J Mech Sci 52(1):31-42

6. Arsecularatne JA, Zhang L (2004) Assessment of constitutive equations used in machining. Key Eng Mater 274:277-282

7. Biermann D, Baschin A (2009) Influence of cutting edge geometry and cutting edge radius on the stability of micromilling processes. Prod Eng 3(4-5):375-380
8. Carroll JT, Strenkowski JS (1988) Finite element models of orthogonal cutting with application to single point diamond turning. Int J Mech Sci 30(12):899-920

9. Chen L, El-Wardany T, Harris W (2004) Modelling the effects of flank wear land and chip formation on residual stresses. CIRP Ann-Manuf Technol 53(1):95-98

10. Davies M, Cao Q, Cooks A, Ivester R (2003) On the measurement and prediction of temperature fields in machining aisi 1045 steel. CIRP Ann-Manuf Technol 52(1):77-80

11. Denkena B, Lucas A, Bassett E (2011) Effects of the cutting edge microgeometry on tool wear and its thermo-mechanical load. CIRP Ann-Manuf Technol 60(1):73-76

12. Dirikolu M, Childs T, Maekawa K (2001) Finite element simulation of chip flow in metal machining. Int J Mech Sci 43(11):26992713

13. Ee K, Dillon O, Jawahir I (2005) Finite element modeling of residual stresses in machining induced by cutting using a tool with finite edge radius. Int J Mech Sci 47(10):1611-1628

14. Guo Y, Anurag S, Jawahir I (2009) A novel hybrid predictive model and validation of unique hook-shaped residual stress profiles in hard turning. CIRP Ann-Manuf Technol 58(1):81-84

15. Höglund U (1976) Skäreggens förslitningsprocess i mikroskala: fysikaliska villkor-förslitningsmekanismer. PhD Thesis, Chalmers University of Technology

16. Huang Y, Liang S (2003) Cutting forces modeling considering the effect of tool thermal property application to cbn hard turning. Int J Mach Tools Manuf 43(3):307-315

17. Johnson GR, Cook WH (1983) A constitutive model and data for metals subjected to large strains, high strain rates and high temperatures. In: Proceedings of the 7th International Symposium on Ballistics, vol 21, The Netherlands, pp 541-547

18. Kalhori V, Lundblad M, Lindgren L (1997) Numerical and experimental analysis of orthogonal metal cutting. J Manuf Science and Engieneering: Trans Of ASME:1-10

19. Klocke F, Raedt HW, Hoppe S (2001) 2d-fem simulation of the orthogonal high speed cutting process. Mach Sci Technol Int J 5(3):323-340

20. Liu K, Melkote SN (2007) Finite element analysis of the influence of tool edge radius on size effect in orthogonal micro-cutting process. Int J Mech Sci 49(5):650-660

21. Mabrouki T, Rigal JF (2006) A contribution to a qualitative understanding of thermo-mechanical effects during chip formation in hard turning. J Mater Process Technol 176(1):214-221

22. Outeiro J, Umbrello D, M'saoubi R (2006) Experimental and numerical modelling of the residual stresses induced in orthogonal cutting of aisi 3161 steel. Int J Mach Tools Manuf 46(14):17861794

23. Özel T (2009) Computational modelling of 3d turning: Influence of edge micro-geometry on forces, stresses, friction and tool wear in pcbn tooling. J Mater Process Technol 209(11):51675177

24. Özel T, Altan T (2000) Determination of workpiece flow stress and friction at the chip-tool contact for high-speed cutting. Int $\mathrm{J}$ Mach Tools Manuf 40(1):133-152

25. Özel T, Zeren E (2004) Determination of work material flow stress and friction for fea of machining using orthogonal cutting tests. $\mathrm{J}$ Mater Process Technol 153:1019-1025

26. Shet C, Deng X (2000) Finite element analysis of the orthogonal metal cutting process. J Mater Process Technol 105(1):95-109

27. Ståhl JE (1986) Skäreggars spontanhaverier. PhD Thesis, Lund University

28. Ståhl JE SECO Tools A (2012a) Metal cutting: theories and models. Lund University, p 195

29. Ståhl JE SECO Tools A (2012b) Metal cutting: theories and models. Lund University, p 44 
30. Ståhl JE SECO Tools A (2012c) Metal cutting: theories and models. Lund University, p 525

31. Stavropoulos P, Papacharalampopoulos A, Vasiliadis E, Chryssolouris G (2016) Tool wear predictability estimation in milling based on multi-sensorial data. Int J Adv Manuf Technol 82(14):509-521

32. Tlusty J, Masood Z (1978) Chipping and breakage of carbide tools. J Manuf Sci Eng 100(4):403-412

33. Ulutan D, Özel T (2013) Determination of tool friction in presence of flank wear and stress distribution based validation using finite element simulations in machining of titanium and nickel based alloys. J Mater Process Technol 213(12):2217-2237
34. Woxen R (1932) A theory and equation for tool life of lathe tools. IVA Hadlingar Stockholm:119

35. Yen YC, Jain A, Altan T (2004) A finite element analysis of orthogonal machining using different tool edge geometries. J Mater Process Technol 146(1):72-81

36. Zhang Y, Mabrouki T, Nelias D, Gong Y (2011) Chip formation in orthogonal cutting considering interface limiting shear stress and damage evolution based on fracture energy approach. Finite Elem Anal Des 47(7):850-863

37. Zhou J, Sturesson P, Sandqvist H, JE Ståhl (1994) An approach for on-line cutting edge stress estimation. Int J Mach Tools Manuf 34(5):741-751 